\title{
The Integrated Biomarker Response: a suitable tool to evaluate toxicity of metal-based nanoparticles
}

Devin $\mathrm{S}^{1}$, Buffet $\mathrm{PE}^{2}$, Châtel $\mathrm{A}^{2}$, Perrein-Ettajani $\mathrm{H}^{2}$, Valsami-Jones $\mathrm{E}^{3}$, Mouneyrac $\mathrm{C}^{2}$.

${ }^{1}$ Université de Lorraine, Laboratoire interdisciplinaire des environnements continentaux

(LIEC), CNRS UMR 7360, Campus Bridoux, rue du Général Delestraint, F-57070 Metz,

France

${ }^{2}$ UBL, Université Catholique de l'Ouest, Laboratoire Mer, Molécules, Santé (MMS,

EA2160), 3 Place André Leroy, F-49000 Angers Cedex 01, France

${ }^{3}$ School of Geography, Earth and Environmental Sciences, University of Birmingham,

Edgbaston, Birmingham B15 2TT, UK

E-mail contact: catherine.mouneyrac@uco.fr , Phone number : +33 (0)2 41816645

Keywords: Integrated Biomarker Response, nano(eco)toxicology, bivalve, ragworm 


\section{Abstract}

Nanotechnology is a much promising field of science and technology with applications in a wide range of areas such as electronics, biomedical applications, energy, and cosmetics. Metal-based engineered nanoparticles (ENPs) represent the largest number of ENPs such as silver, gold, copper oxide $(\mathrm{CuO})$, zinc oxide $(\mathrm{ZnO})$, cadmium sulfide $(\mathrm{CdS})$ nanoparticles. The toxicity of metal-based NPs may be either due to their specific physical characteristics as NPs or to the specific toxicity of metals released from NPs under environmental conditions. In this study we evaluated toxicity effects of ENPs ( $\mathrm{Ag}, \mathrm{Au}, \mathrm{CuO}, \mathrm{CdS}, \mathrm{ZnO})$ and their ionic control part on two endobenthic species: the ragworm Hediste diversicolor and the bivalve Scrobicularia plana. A suite of complementary biomarkers was used to reveal toxicity effects. A common challenge in multibiomarkers studies is to go beyond an independent interpretation of each one, and to really assess a global response of individuals. The Integrated Biomarker Response (IBR) was calculated for both species exposed to the different metalbased ENPs studied or to their soluble metal counterpart to provide efficient and easy tools for environmental managers. We evidence that metal-based NPs lead to an overall difference in biological responses from the control and their soluble counterpart. The IBR could thus be considered as an efficient tool to transfer research results to stakeholders with possible implementation for regulatory purposes. 


\section{Introduction}

Nanotechnology is a rapidly expanding field of research continuously producing nanomaterials (NMs), which may be incorporated into consumer products such as cosmetics, paints, textiles and electronic appliances. Among commercially important engineered nanoparticles (ENPs), metal-based ENPs comprise the largest number of ENPs such as silver, gold, copper oxide $(\mathrm{CuO})$, zinc oxide $(\mathrm{ZnO})$ and cadmium sulphide $(\mathrm{CdS})$ nanoparticles. Due to this rapid diffusion of commercial nano- products, it is inevitable that ENPs will enter the aquatic environment (lakes, rivers, estuaries and seas) despite safe guards (Sun et al., 2016). Increasing studies shown that NPs may be more toxic compared with larger particles of the same substance and NMs risks assessment represents a real challenge for (eco)toxicologists.

In nano-ecotoxicology, early studies were mainly conducted with freshwater species with less than $20 \%$ of published papers on marine species. During the last decade, publications in marine species has risen considerably (up to $38 \%$ of the total published papers) focusing on NPs bioaccumulation, sub-lethal effects and mechanisms of action (Canesi and Corsi, 2016). However, major scientific gaps still need to be filled. In seawater, NPs become rapidly agglomerated, leading to their deposition onto the sediment surface. In the present work, two endobenthic species have been selected; the ragworm Hediste diversicolor and the bivalve mollusc Scrobicularia plana since they play an important role in the structure and functionning of marine ecosystems.

Despite the influence of confounding factors on biomarker responses, those responding relatively rapidly to stress have high toxicological relevance (Amiard-Triquet and Berthet, 2015). Among changes in biological activities induced by NPs, reactive oxygen species (ROS) generation is one of the most frequently reported NP-associated toxicities. Thus, antioxidant defenses such as catalase (CAT), glutathion-S transferase (GST), superoxide 
dismutase (SOD) and thiobarbyturic acid substances (TBARs) to reveal if this protective antioxidant effect is overwhelmed are of particular interest. In addition, metallothionein (MT), a cystein-rich protein which is involved both in antioxidant defense and metal detoxification, also increases in presence of NPs. The activation of caspase (CSP), a cysteine protease, revealing of apoptosis processes has been previously shown in bivalves exposed to metalbased NPs (Mouneyrac et al., 2014). Defence against the stress caused by NPs may be energy consuming and lactate dehydrogenase (LDH) activity is involved when a huge amount of energy is rapidly required.

A common challenge in multibiomarker studies is to go beyond an independent interpretation of each one, and to assess the global response of individual biomarkers. This global assessment also simplifies their interpretation in biomonitoring programs. Among the indices proposed to integrate individual biomarker responses, the most popular is the Integrated Biomarker Response (IBR) initially proposed by Beliaeff and Burgeot (2002) and refined some years later by Devin et al (2014). The IBR approach is a method that provides both a graphical synthesis of the different biomarker responses and a numeric value that integrates all these responses at once. While this index has been already used in field surveys (PainDevin et al., 2014) to our best knowledge, until now the potential use of IBR has never been tested in nano(eco)toxicological studies.

The main objectives of the present work were: i) to test the suitability of the use of the IBR to determine if a range of common ENPs $(\mathrm{CuO}, \mathrm{Ag}, \mathrm{ZnO}, \mathrm{Au}, \mathrm{CdS})$ may exert toxicity through mechanisms which were distinct from the mechanisms of toxicity for dissolved ions and ii) to provide efficient and easy tools for environmental managers. 


\section{Material and methods}

\section{Chemicals used}

A set of ENPs of different core compositions: metals: Ag (40-45 nm), Au (5 nm, $15 \mathrm{~nm}, 40$ $\mathrm{nm})$; metal oxides: $\mathrm{CuO}(1-100 \mathrm{~nm}), \mathrm{ZnO}(21-34 \mathrm{~nm})$; and a metal chalgonenides: $\mathrm{CdS}$ (5-10 $\mathrm{nm}$ ) were selected. The synthesis protocols and characterization in experimental media are detailed in previous published papers (Buffet et al., 2011, 2012, 2013a, 2013b, 2014a, 2014b, Pan et al., 2012). The strategy to select the concentrations of exposure was established for $\mathrm{Cu}$ and $\mathrm{Ag}$ on levels recorded as the maximum concentrations $\left(10 \mu \mathrm{gL}^{-1}\right)$ of total $\mathrm{Ag}$ or $\mathrm{Cu}$ in marine environments highly contaminated by these metals (Eisler, 2007). For Cd, the same exposure concentration $\left(10 \mu \mathrm{gL}^{-1}\right)$ corresponded to sub-lethal effects observed at concentrations between $0.5 \mu \mathrm{g} \mathrm{L} \mathrm{L}^{-1}$ and $10 \mu \mathrm{g} \mathrm{L}^{-1}$ of this metal towards marine organisms (Eisler, 2007). For gold, since this metal is very inert, an exposure concentration of $100 \mu \mathrm{g} \mathrm{L}^{-1}$ was used to induce measurable adverse effects. Finally we used predicted doses $(3 \mathrm{mg} \mathrm{ZnO}$ $\mathrm{kg}^{-1}$ sediment) for $\mathrm{ZnO}$ NPs, to conduct exposures at environmentally realistic concentrations (Tiede et al., 2009).

\section{Experimental designs}

The different experimental approaches (laboratory microcosms, outdoor mesocosms) have been fully described in Mouneyrac et al. (2014). Briefly, for waterborne exposures, both species ( $S$. plana, $H$. diversicolor) were exposed during two weeks to: 1) seawater only (controls), 2) metal-based ENPs ( $\mathrm{CuO}, \mathrm{Ag}, \mathrm{CdS}, \mathrm{Au})$ and 3) soluble metals $(\mathrm{Ag}, \mathrm{Cu}, \mathrm{Cd})$. Concerning dietary exposure, bivalves were fed with algae (Nitzschia) previously contaminated by nanoparticulate forms (Ag NPs, CdS NPs) or soluble metal forms (Ag, Cd) whereas ragworms were fed with pieces of $H$. diversicolor exposed to soluble or NP forms (Ag, CdS) or pieces of control worms from the waterborne exposure experiment (Buffet et al., 
2013b, 2014b). For sediment exposure, bivalves and worms were exposed to isotopically labelled ${ }^{67} \mathrm{ZnO}$ NPs (to separate $\mathrm{Zn}$ derived from $\mathrm{ZnO}$ NPs from pre-existing $\mathrm{Zn}$ ) added in the surface water (Buffet et al., 2012). The influence of the stabilizing solution agent (diethylene glycol: DEG) has also been taken into account. Three treatments were carried out: 1) natural seawater only (controls), 2) ${ }^{67} \mathrm{ZnO}$ NPs in DEG, 3) DEG alone at the same concentration as added with NPs. Experiments in outdoor mesocosms $(\mathrm{Cu}, \mathrm{Ag})$ were conducted during 21 days. Implementation of experimental mesocosms has been described in details in Buffet et al. (2013a). Three treatments were carried out: 1) natural seawater only (controls), 2) soluble metal forms $(\mathrm{Cu}, \mathrm{Ag})$ and 3) $\mathrm{Ag}$ NPs or CuO NPs.

\section{Biomarker analysis}

Toxicity effects towards $S$. plana and $H$. diversicolor were compared between the nanoparticulate form of metals and their soluble counterpart $(\mathrm{Ag}, \mathrm{Cu}, \mathrm{Cd})$ using a multibiomarker (CAT, AChE, GST, TBARs, MT, CSP, LDH) approach. Protocols for these biomarker quantifications were extensively described in Buffet et al. $(2011,2012)$ and results are shown in supplementary material (Table S1).

\section{IBR calculation}

The Integrated Biomarker Response (IBR) was calculated for each experiment following the method developed by Devin et al. (2014). The calculation is based on 4 major steps, initially described in Beliaeff and Burgeot (2002). The first step consists in the standardisation of the mean value of each biomarker obtained for a condition, called $\mathrm{X}$, using the mean value for all conditions (m) and the standard deviation for all conditions (s) to produce a value called Y: $\mathrm{Y}=(\mathrm{X}-\mathrm{m}) / \mathrm{s}$. After this standardisation, we computed the $\mathrm{Z}$ value; $\mathrm{Z}=\mathrm{Y}$ or $\mathrm{Z}=-\mathrm{Y}$ whether an activation or an inhibition of the biomarker was expected in response to a contamination. The value $\mathrm{S}$ was finally computed, with $\mathrm{S}=\mathrm{Z}+|\mathrm{Min}|$, where Min is the minimal value observed for 
all exposure conditions for each biomarker, and finally plotted on a radar diagram. These $\mathrm{S}$ values thus represent the gradient of values for each biomarker in the different exposure conditions, with highest values corresponding to the highest biological effects. The IBR was calculated as the total area displayed by the radar diagram. The initial version of the IBR only computed one value that is strongly dependent on the biomarker arrangement along the radar diagram. To solve this problem, Devin et al. (2014) proposed to compute all IBR values corresponding to every possible order of the biomarkers along the radar diagram, thanks to a permutation procedure leading to $(\mathrm{k}-1)$ possible values, where $\mathrm{k}$ is the number of biomarkers. Here we computed IBR values independently for each experiment and for each species $(S$. plana, $H$. diversicolor), thus only allowing within experiment comparisons.

\section{Statistical analysis}

IBR values were compared between exposure conditions for each experiment. Values were always normally distributed and homoscedasticity was respected, allowing using student t-test to assess between condition differences. However, the permutation procedure which needs to compute all possible IBR for each experiment leads to the calculation of up to 720 different values per condition in an experiment for $H$. diversicolor, and up to 5040 for S. plana. This huge sample size induces a bias in statistical tests that becomes too much powerful and allows to evidence statistical significance that are biologically meaningless. To get around this problem, we first set to 1 the magnitude of the effect size (a dimensionless parameter that quantify IBR differences between two conditions) that is biologically meaningful. With this basis, we then calculate the sample size allowing to evidence such differences, by setting the statistical power to 0.8 that is the value generally admitted as good. This led to a sample size of ten values. To encompass the variability of IBR among permutations, we repeat 100 times a random sampling of ten IBR values among all the ones calculated within each exposure condition, and perform each time a bilateral paired student t-test between the two samples. 
The p-value of each test was stored in a vector, which was then corrected for multiple comparisons following the procedure of Benjamini and Hochberg (1995). Finally, the p-value we kept was the mean of the 100 corrected p-values.

\section{Results}

\section{IBR values}

The means \pm standard deviations of IBR calculated for both species (H. diversicolor, S. plana) for each exposure condition (microcosms, mesocosms) and treatments (controls: seawater without any contaminants, ENPs, soluble metal) are illustrated in Figure 1 and 2. For both species, standardized values of each biomarker tested (GST, CAT, SOD, AChE, TBARs, LDH, CSP) within each exposure condition and treatment are shown in Table 1. It evidenced statistically significant differences in global biomarker responses according to the different treatments (Table 1). Except for S. plana exposed to Ag in laboratory microcosms (waterborne exposure) and in outdoor mesocosms, and to $\mathrm{Cu}$ in laboratory microcosms controls were always significantly different from both metal forms (nanoparticulate, soluble).

Concerning the influence of the route of exposure, we noticed, in both species, differences in IBR values between waterborne and dietary exposure to $\mathrm{Cd}$ and $\mathrm{Ag}$. In worms, greater values of IBR were observed in animals exposed in laboratory microcosms to soluble Ag (seawater and contaminated food) compared with Ag NPs. An inverse pattern was observed in both species exposed to $\mathrm{Cd}$ (waterborne and dietary exposures). For bivalves exposed to $\mathrm{Ag}$ contaminated food, greater values of IBR were shown in organisms exposed to soluble Ag vs Ag NPs whereas the inverse was noted for waterborne exposure. In both species exposed either in laboratory microcosms as in outdoor mesocosms, greater IBR values were observed in animals exposed to $\mathrm{CuO}$ NPs compared with soluble $\mathrm{Cu}$. For $\mathrm{Zn}$, the highest IBR values 
were found in bivalves exposed to $\mathrm{ZnO}$ NPs compared with those exposed to the stabilizing agent (DEG) whereas the contrary was observed in worms.

Finally, for gold, where no soluble form was used, we showed a size-effect relationship for both species. Greater IBR values were observed in H. diversicolor and S. plana exposed to 45 $\mathrm{nm} \mathrm{Au}$ NPs compared with $5 \mathrm{~nm}$ and $15 \mathrm{~nm}$ Au NPs.

\section{Relative importance of each biomarker in IBR values}

If we focused on standardized values ( $\mathrm{S}$ values described earlier, Table 2), we can define which biomarkers had the most important weight in the final IBR values. Great differences in the relative importance of each biomarker in IBR values were found between species $(H$. diversicolor, $\mathrm{S}$. plana), metal ( $\mathrm{Ag}, \mathrm{Cu}, \mathrm{Zn}, \mathrm{Cd} \mathrm{Au})$ and metal forms (nanoparticulate, soluble). Concerning silver (laboratory microcosms, outdoor mesocosms), the highest responses were observed for both species exposed to soluble Ag. The most important weight of biomarkers in IBR values was attributed to those involved in oxidative-stress such as GST, SOD, CAT TBARs. The same pattern was observed in bivalves (S. plana) exposed to Ag NPs whereas in worms (H. diversicolor), the induction of $\mathrm{LDH}$ seemed preponderant comparatively with the other biomarkers quantified. For $\mathrm{Cu}$ and $\mathrm{Cd}$, nanoparticulate form ( $\mathrm{CuO}$ NPs, $\mathrm{CdS}$ NPs) appeared to induce stronger effects (oxidative-stress, neurotoxicity, apoptosis) than soluble forms. In bivalves exposed to $\mathrm{ZnO} \mathrm{NPs}$, stronger effects on biomarker responses were observed in comparison with those exposed to the stabilizing solution (DEG) while in worms an inverse pattern was found. Finally, for Au, highest S values were observed for the highest NP size (45 nm), except for TBARs that evidenced an inverse pattern.

\section{Discussion}


One main challenge in nanotoxicology of metal-based NPs is to determine if toxicity is due to their specific physical characteristics as NPs or to the toxicity of metals released from NPs or a combination of both. Thus, in the present paper we compared toxicity effects in $H$. diversicolor and S. plana using a set of biomarkers between organisms exposed to various metal-based NPs and those exposed to their soluble counter-part. The recognition of the value of biomarkers in the evaluation of pollution effects in the marine environment is a step forward for assessing pollution effects including those potentially induced by ENPs (Mouneyrac et al., 2014). Such early warnings of ENPs environmental impacts are extremely important, as timely detection will allow corrective measures to be undertaken, avoiding irreversible effects on the whole ecosystem. The biomarkers selected in the present work have to be able to reveal different toxic effects endured by organisms exposed to the ENPs selected. In order to simplify their interpretation we used the IBR index integrating individual responses of each biomarker tested.

Results shown in all cases that IBR was able to discriminate toxicity effects in both species (H. diversicolor, S. plana) between those exposed to ENPs (CuO NPs, Ag NPs, CdS NPs) and their soluble counter-part $(\mathrm{Cu}, \mathrm{Ag}, \mathrm{Cd})$. The highest IBR values were observed for the soluble silver form (vs nanoparticulate), while nanoparticulate copper (CuO NPs) or CdS NPs induced greater effects ( $v s$ soluble form). These responses were not surprising since Ag dissolution from Ag NPs, revealed by Diffusive Gradient in Thin films (DGT) tools, was observed in the experimental media (microcosms, mesocosms) with time of exposure (Buffet et al., 2013b, 2014 a). These results are in accordance with previous studies of the relative toxicity of $\mathrm{Ag}$ NPs and Ag as soluble form to aquatic species demonstrating the determinant role of soluble Ag in the observed toxicity resulting from Ag NP exposure (Navarro et al., 2008). In contrast, for $\mathrm{CuO} \mathrm{NPs,} \mathrm{no} \mathrm{measurable} \mathrm{release} \mathrm{of} \mathrm{labile} \mathrm{Cu}$ was measured using DGT in the experimental media during the time of exposure (16 days: microcosms, 21 days: mesocosms) 
(Buffet et al., 2011). For CdS NPs, the labile Cd fraction from CdS in seawater were two times lower than values quantified in DGT from soluble Cd exposure tanks suggesting that a significant fraction of CdS NPs remained in nanoparticulate form (Buffet et al., 2014b). Greater IBR values were observed in both species exposed to $45 \mathrm{~nm}$ Au NPs compared with 5 $\mathrm{nm}$ and $15 \mathrm{~nm} \mathrm{Au}$ NPs. These results can be related to greater bioaccumulation of $45 \mathrm{~nm} \mathrm{Au}$ NPs compared with $5 \mathrm{~nm}$ Au NPs and $15 \mathrm{~nm}$ Au NPs (Pan et al, 2012).

The most studied nanotoxicity mechanism is ROS generation, whose overproduction can lead to oxidative stress in the organism tissues. Results of the present study show that biomarkers playing the most important weight in the IBR calculation were CAT, GST, SOD and TBARs in both species. Moreover, the oxidative stress triggered the activation of cytosolic CSP suggesting that these NPs exerted cytotoxicity by an apoptotic process. These effects were observed despite the fact that animals activated antioxidant defences.

In the paper from Buffet et al. (2013b), soluble Ag and Ag NPs induced in S. plana oxidative stress revealed by increased CAT, GST and SOD activities but no differences in these biomarker responses between Ag NPs and soluble Ag were observed. In the present work, the use of the IBR was able to reveal greater responses in organisms exposed to soluble $\mathrm{Ag}$ compared with Ag NPs. In worms ( $H$. diversicolor), the induction of LDH seemed preponderant comparatively with the other biomarkers quantified. Activation of defences to cope with chemical stress is metabolically costly and could explain the involvement of LDH since this enzyme plays an important function in anaerobic metabolism (Moreira et al., 2006). Our results shown a remarkable contribution of AChE in the IBR calculation of both species exposed to $\mathrm{CuO}$ NPs and $\mathrm{CdS}$ NPs compared with soluble metals $(\mathrm{Cu}, \mathrm{Cd})$ and are in accordance with previous published papers showing greater burrowing impairments of organisms exposed to these NPs vs soluble metals (Mouneyrac et al., 2014). 
In conclusion, the IBR appears as a suitable tool to provide a comprehensive assessment of the health status of species exposed to sub-lethal concentrations of metal-based NPs. To date a major challenge for regulatory purposes is the exploration of large datasets from previous nano(eco)toxicity studies. In this sense, the application of IBR could be a sustainable way for providing easy, efficient and non-expensive tool for environmental managers.

\section{Acknowledgements}

The research leading to these results has received funding from the European Union Seventh Framework Programme (FP7/2007-2013) under grant agreement no. 214478 (NanoReTox).

\section{References}

Amiard-Triquet C, Berthet B. 2015. Individual biomarkers. In: Amiard-Triquet C, Amiard JC, Mouneyrac C, eds. Aquatic Ecotoxicology. London: Academic Press, 153-182.

Beliaeff B, Burgeot T. 2002. Integrated Biomarker Response : A useful tool for ecological risk assessment. Environ Toxicol Chem 21:1316-1322.

Benjamini Y, Hochberg Y. 1995. Controlling the false discovery rate: a practical and powerful approach to multiple testing. J R Stat Soc Series B 57: 289-300.

Buffet PE, Fossi Tankoua O, Pan JF, Berhanu D, Herrenknecht C, Poirier L, Amiard-Triquet C, Amiard JC, Bérard JB, Risso C, Guibbolini M, Roméo M, Reip P, Valsami-Jones E, Mouneyrac C. 2011. Behavioural and biochemical responses of two marine invertebrates Scrobicularia plana and Hediste diversicolor to copper oxide nanoparticles. Chemosphere 84:166-174. 
Buffet PE, Amiard-Triquet C, Dybowska A, Risso-de Faverney C, Guibbolini M, ValsamiJones E, Mouneyrac C. 2012. Fate of isotopically labeled zinc oxide nanoparticles in sediment and effects on two endobenthic species the clam Scrobicularia plana and the ragworm Hediste diversicolor. Ecotoxicol Environ Saf 84:191-198.

Buffet PE, Richard M, Caupos F, Vergnoux A, Perrein-Ettajani H, Luna- Acosta A, Akcha F, Amiard JC, Amiard-Triquet C, Guibbolini M, Risso-de Faverney C, Thomas-Guyon H, Reip P, Dybowska A, Berhanu D, Valsami-Jones E, Mouneyrac C. 2013a. Mesocosm study of fate and effects of $\mathrm{CuO}$ nanoparticles on endobenthic species (Scrobicularia plana, Hediste diversicolor). Environ Sci Technol 47:1220-1228.

Buffet PE, Pan JF, Poirier L, Amiard-Triquet C, Amiard JC, Gaudin P, Risso-de Faverney C, Guibbolini M, Gilliland D, Valsami-Jones E, Mouneyrac C. 2013b. Biochemical and behavioural responses of the endobenthic bivalve Scrobicularia plana to silver nanoparticles in seawater and microalgal food. Ecotoxicol Environ Saf 89:117-124.

Buffet PE, Zalouk Vergnoux A, Châtel A, Berthet B, Perrein-Ettajani H, Poirier L, LunaAcosta A, Thomas-Guyon H, Risso-de-Faverney C, Guibbolini M, Gilliland D, ValsamiJones E, Mouneyrac C. 2014a. A marine mesocosm study on the environmental fate of silver nanoparticles and toxicity effects on two endobenthic species: the ragworm Hediste diversicolor and the bivalve mollusc Scrobicularia plana. Sci Total Environ 470-471C:11511159. 
Buffet PE, Poirier L, Zalouk-Vergnoux A, Lopes C, Amiard JC, Gaudin P, Faverney R, Guibbolini M, Gilliland D, Perrein H, Valsami-Jones E, Mouneyrac C. 2014b. Biochemical and behavioural responses of the marine polychaete Hediste diversicolor to cadmium sulfide quantum dots (CdS QDs): waterborne and dietary exposure. Chemosphere 100:63-70.

Canesi L, Corsi I. 2016. Effects of nanomaterials on marine invertebrates. Sci. Total Environ 565:933-940.

Devin S, Burgeot T, Giambérini L, Minguez L and Pain-Devin S. 2014. The Integrated Biomarker Response revisited: optimization to avoid misuse. Environ Sci Pollut Res 21:24482454.

Eisler R. 2007. Eisler's encyclopedia of environmentally hazardous priority chemicals. Elsevier Science Ltd, Oxford.

Mouneyrac C, Buffet PE, Poirier L, Zalouk-Vergnoux A, Guibbolini M, Faverney CR, Gilliland D, Berhanu D, Dybowska A, Châtel A, Perrein-Ettajni H, Pan J-F, Thomas-Guyon H, Reip P and Valsami-Jones E. 2014. Fate and effects of metal-based nanoparticles in two marine invertebrates, the bivalve mollusc Scrobicularia plana and the annelid polychaete Hediste diversicolor. Environ Sci Pollut Res 21:7899-7912.

Navarro E, Piccapietra F, Wagner B, Marconi F, Kaegi R, Odzak N, Sigg L, Behra R. 2008. Toxicity of silver nanoparticles to Chlamydomonas reinhardtii. Environ Sci Technol 42:89598964. 
Pain-Devin S, Cossu-Leguille C, Geffard A, Giambérini L, Jouenne T, Minguez L, Naudin B, Parant M, Rodius F, Tarnowska K, Daguin-Thiébaut C, Viard F and Devin S. 2014. Towards a better understanding of biomarker response in field populations: a case study in eight populations of zebra mussels. Aquatic Tox 155: 52-61.

Pan JF, Buffet PE, Poirier L, Amiard-Triquet C, Gilliland D, Joubert Y, Pilet P, Guibbolini M, Risso De Faverney C, Roméo M, Valsami-Jones E, Mouneyrac C. 2012. Size dependent bioaccumulation and ecotoxicity of gold nanoparticles in an endobenthic invertebrate: the Tellinid clam Scrobicularia plana. Environ Pollut 168:37-43.

Tiede K, Hassellöv M, Breitbarth E, Chaudhry Q, Boxall ABA. 2009. Considerations for environmental fate and ecotoxicity testing to support environmental risk assessments for engineered nanoparticles. J Chromatogr A 1216(3):503-509.

Sun, TY, Bornhoft NA., Hungerbuhler K, Nowack B. 2016. Dynamic Probabilistic Modeling of Environmental Emissions of Engineered Nanomaterials. Environ Sci Technol.50:47014711. 

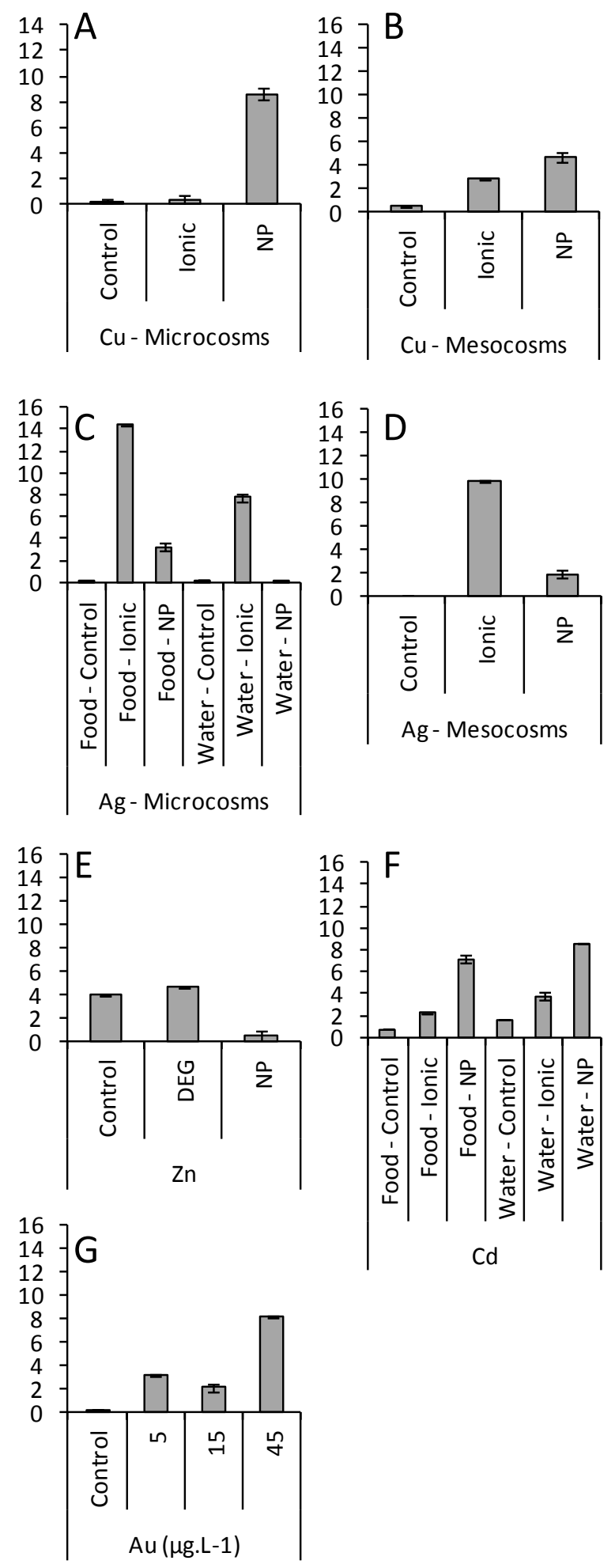

Figure 1. Mean and standard deviation of the set of IBR values obtained through permutation for Hediste diversicolor. The seven panel correspond to the different experiments: $\mathrm{Cu}$, in microcosm (A) and mesocosm (B); Ag, in microcosm (C) and mesocosm (D); Zn (E), Cd (F) and $\mathrm{Au}(\mathrm{G})$, in microcosms only. 

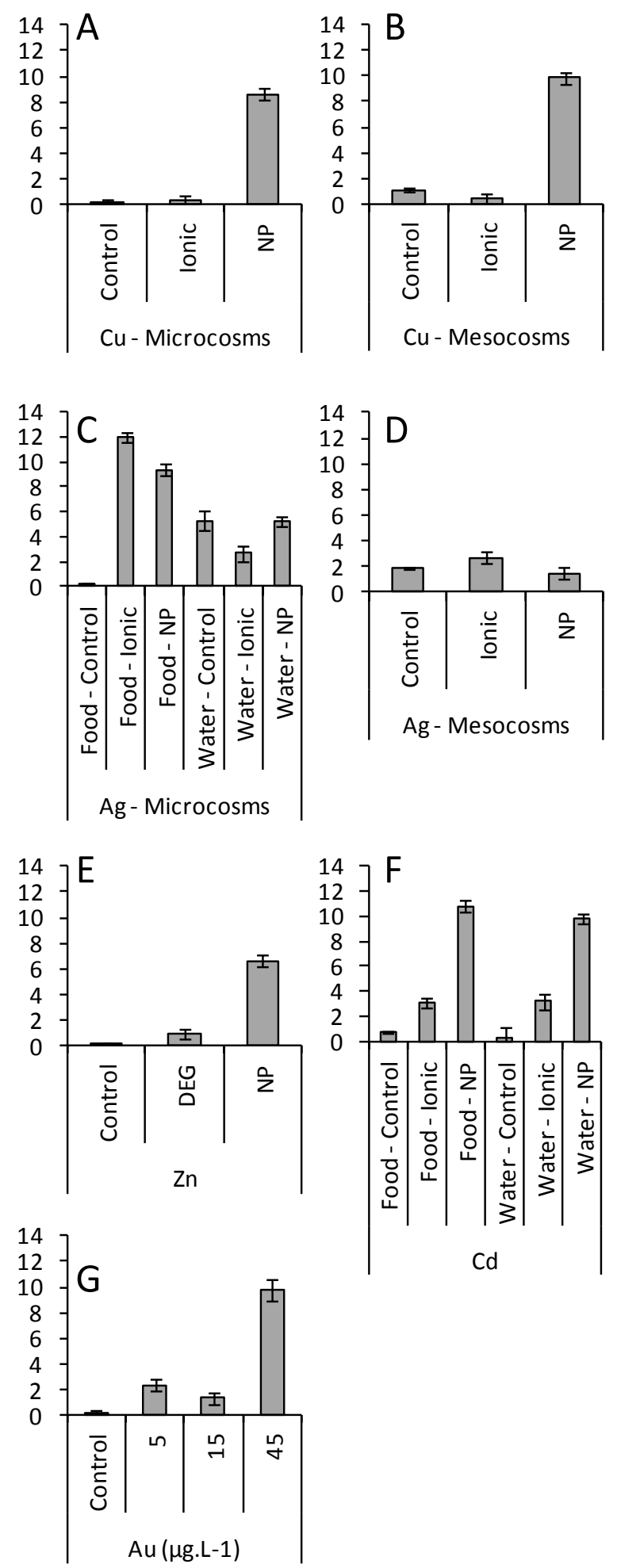

Figure 2. Mean and standard deviation of the set of IBR values obtained through permutation for Scrobicularia plana. The seven panel correspond to the different experiments: $\mathrm{Cu}$, in microcosm (A) and mesocosm (B); Ag, in microcosm (C) and mesocosm (D); Zn (E), Cd (F) and $\mathrm{Au}(\mathrm{G})$, in microcosms only. 


\begin{tabular}{|c|c|c|c|c|c|}
\hline \multirow[t]{2}{*}{ Experiment } & \multicolumn{3}{|c|}{ Conditions } & \multirow{2}{*}{$\frac{H . \text { diversicolor }}{<0.001}$} & \multirow{2}{*}{$\frac{\text { S. plana }}{<0.001}$} \\
\hline & Food - Control & vs. & Food - Soluble & & \\
\hline \multirow{8}{*}{ Ag - Microcosms } & Food - Control & vs. & Food - NP & $<0.001$ & $<0.001$ \\
\hline & Food-Soluble & vs. & Food - NP & $<0.001$ & $<0.001$ \\
\hline & Water - Control & vs. & Water-Soluble & $<0.001$ & $<0.001$ \\
\hline & Water - Control & vs. & Water - NP & $<0.001$ & 0.43 \\
\hline & Water-Soluble & vs. & Water - NP & $<0.001$ & $<0.001$ \\
\hline & Food - Control & vs. & Water - Control & 0.006 & $<0.001$ \\
\hline & Food-Soluble & vs. & Water-Soluble & $<0.001$ & $<0.001$ \\
\hline & Food - NP & vs. & Water - NP & $<0.001$ & $<0.001$ \\
\hline \multirow{3}{*}{$\mathrm{Ag}-\mathrm{Mesocosms}$} & Control & vs. & Soluble & $<0.001$ & 0.18 \\
\hline & Control & vs. & NP & $<0.001$ & 0.28 \\
\hline & Soluble & vs. & NP & $<0.001$ & 0.002 \\
\hline \multirow{3}{*}{$\mathrm{Cu}$ - Microcosms } & Control & vs. & Soluble & 0.015 & 0.54 \\
\hline & Control & vs. & NP & $<0.001$ & $<0.001$ \\
\hline & Soluble & vs. & NP & $<0.001$ & $<0.001$ \\
\hline \multirow{3}{*}{$\mathrm{Cu}-\mathrm{Mesocosms}$} & Control & vs. & Soluble & $<0.001$ & 0.01 \\
\hline & Control & vs. & NP & $<0.001$ & $<0.001$ \\
\hline & Soluble & vs. & NP & $<0.001$ & $<0.001$ \\
\hline \multirow{3}{*}{$\mathrm{Zn}$} & Control & vs. & DEG & 0.1 & 0.002 \\
\hline & Control & vs. & NP & $<0.001$ & $<0.001$ \\
\hline & DEG & vs. & NP & $<0.001$ & $<0.001$ \\
\hline \multirow{6}{*}{$\mathrm{Au}\left(\mu \mathrm{g} \cdot \mathrm{L}^{-1}\right)$} & Control & vs. & 5 & $<0.001$ & $<0.001$ \\
\hline & Control & vs. & 15 & $<0.001$ & $<0.001$ \\
\hline & Control & vs. & 45 & $<0.001$ & $<0.001$ \\
\hline & 5 & vs. & 15 & 0.02 & 0.018 \\
\hline & 5 & vs. & 45 & $<0.001$ & $<0.001$ \\
\hline & 15 & vs. & 45 & $<0.001$ & $<0.001$ \\
\hline \multirow{9}{*}{$\mathrm{Cd}$} & Food - Control & vs. & Food - Soluble & $<0.001$ & $<0.001$ \\
\hline & Food - Control & vs. & Food - NP & $<0.001$ & $<0.001$ \\
\hline & Food-Soluble & vs. & Food - NP & $<0.001$ & $<0.001$ \\
\hline & Water - Control & vs. & Water-Soluble & $<0.001$ & $<0.001$ \\
\hline & Water - Control & vs. & Water - NP & $<0.001$ & $<0.001$ \\
\hline & Water - Soluble & vs. & Water - NP & $<0.001$ & $<0.001$ \\
\hline & Food - Control & vs. & Water-Control & 0.058 & 0.007 \\
\hline & Food-Soluble & vs. & Water-Soluble & $<0.001$ & 0.45 \\
\hline & Food - NP & vs. & Water - NP & 0.026 & 0.033 \\
\hline
\end{tabular}

Table I: Statistical differences between conditions (controls, soluble metal, nanoparticles) within each experiment. Differences were obtained with a student t-test with the False Detection Rate risk correction. Values in bold correspond to non-significant differences. 


\begin{tabular}{|c|c|c|c|c|c|c|c|c|c|c|c|c|c|c|c|c|}
\hline & & & & & & & & & & & & & & & & \\
\hline & & \multicolumn{7}{|c|}{ H. diversicolor } & \multicolumn{8}{|c|}{ S. plana } \\
\hline & & GST & SOD & CAT & Ache & TBARS & LDH & CSP & GST & SOD & CAT & Ache & TBARS & LDH & MT & CSP \\
\hline \multirow{6}{*}{$\mathrm{Ag}-\mathrm{Microcos} \mathrm{ms}$} & Food - Control & 0,4 & 0,3 & 0,0 & 0,2 & 0,4 & 0,0 & 0,0 & 0,0 & 0,0 & 0,0 & 0,0 & 0,0 & 2,2 & 0,0 & 0,4 \\
\hline & Food - Soluble & 2,4 & 2,2 & 2,2 & 1,9 & 2,6 & 2,2 & 2,6 & 2,9 & 2,9 & 2,4 & 1,8 & 2,3 & 2,0 & 0,7 & 1,5 \\
\hline & Food - NP & 1,5 & 1,0 & 0,4 & 1,4 & 0,6 & 2,4 & 0,5 & 2,4 & 2,5 & 2,3 & 1,0 & 1,8 & 2,0 & 0,2 & 2,6 \\
\hline & Water - Control & 0,5 & 0,2 & 0,1 & 0,3 & 0,2 & 0,5 & 0,0 & 1,3 & 2,0 & 0,6 & 2,2 & 2,6 & 0,0 & 2,3 & 0,3 \\
\hline & Water-Soluble & 2,1 & 2,3 & 1,9 & 2,4 & 1,6 & 0,8 & 0,8 & 1,7 & 1,6 & 2,0 & 0,0 & 0,8 & 0,2 & 1,8 & 0,0 \\
\hline & Water - NP & 0,0 & 0,0 & 0,1 & 0,0 & 0,0 & 1,9 & 0,0 & 1,5 & 1,7 & 1,9 & 2,1 & 1,0 & 0,6 & 2,1 & 0,2 \\
\hline \multirow{3}{*}{$\mathrm{Ag}-$ Mesocosms } & Control & 0,0 & 0,0 & 0,0 & 0,0 & 0,0 & & 0,0 & 0,0 & 1,9 & 0,0 & 1,9 & 1,9 & & & 0,0 \\
\hline & Soluble & 2,0 & 2,0 & 2,0 & 2,0 & 1,9 & & 1,9 & 2,0 & 0,5 & 1,8 & 0,0 & 0,3 & & & 1,9 \\
\hline & NP & 0,6 & 1,0 & 1,1 & 0,7 & 0,4 & & 1,4 & 1,3 & 0,0 & 1,7 & 0,5 & 0,0 & & & 1,5 \\
\hline \multirow{3}{*}{$\mathrm{Cu}-\mathrm{Microcosms}$} & Control & 0,0 & 2,0 & 0,0 & 2,0 & 0,0 & 1,3 & & 0,0 & 0,0 & 0,0 & 0,0 & 1,9 & 0,8 & & \\
\hline & Soluble & 0,5 & 0,9 & 1,1 & 0,0 & 0,2 & 0,0 & & 0,6 & 0,0 & 0,5 & 1,4 & 0,0 & 0,0 & & \\
\hline & NP & 1,9 & 0,0 & 2,0 & 1,4 & 1,8 & 2,0 & & 2,0 & 1,7 & 1,9 & 1,9 & 1,4 & 2,0 & & \\
\hline \multirow{3}{*}{$\mathrm{Cu}-\mathrm{Mes} o c o s m s$} & Control & 0,0 & 0,0 & 0,0 & 2,0 & 1,9 & 0,0 & 0,0 & 0,0 & 0,4 & 0,0 & 1,3 & 0,8 & 1,8 & 0,0 & 1,0 \\
\hline & Soluble & 0,7 & 1,3 & 1,4 & 0,0 & 0,5 & 2,0 & 1,5 & 0,7 & 0,0 & 1,0 & 0,0 & 0,0 & 0,0 & 1,9 & 0,0 \\
\hline & NP & 2,0 & 2,0 & 1,9 & 1,1 & 0,0 & 0,6 & 1,9 & 2,0 & 1,9 & 2,0 & 2,0 & 2,0 & 1,7 & 1,4 & 2,0 \\
\hline \multirow{3}{*}{$\mathrm{Zn}$} & Control & 0,0 & 2,0 & 0,0 & 1,0 & 1,9 & 1,9 & 1,9 & 0,0 & 1,4 & 0,0 & 0,3 & 0,0 & 0,1 & 0,0 & 0,0 \\
\hline & DEG & 1,0 & 0,0 & 2,0 & 2,0 & 1,4 & 1,4 & 1,5 & 2,0 & 0,0 & 0,4 & 0,0 & 0,0 & 0,0 & 1,9 & 1,0 \\
\hline & NP & 2,0 & 0,7 & 0,8 & 0,0 & 0,0 & 0,0 & 0,0 & 0,6 & 1,9 & 1,9 & 1,9 & 1,8 & 1,8 & 0,6 & 2,0 \\
\hline \multirow{4}{*}{$\mathrm{Au}\left(\mu \mathrm{g} \cdot \mathrm{L}^{-1}\right)$} & Control & 0,0 & 0,0 & 0,0 & 0,6 & 2,2 & 0,0 & & 0,0 & 0,1 & 0,7 & 0,0 & 0,9 & 0,7 & 0,0 & \\
\hline & 5 & 0,5 & 1,9 & 0,4 & 2,1 & 0,0 & 2,2 & & 1,5 & 0,5 & 0,0 & 0,6 & 1,1 & 2,2 & 0,9 & \\
\hline & 15 & 0,8 & 2,1 & 0,7 & 0,0 & 0,4 & 1,7 & & 2,1 & 0,0 & 1,9 & 1,2 & 0,0 & 0,3 & 0,1 & \\
\hline & 45 & 2,3 & 1,9 & 2,3 & 1,9 & 0,4 & 1,9 & & 2,2 & 2,1 & 2,1 & 2,4 & 2,4 & 0,0 & 2,2 & \\
\hline \multirow{6}{*}{$\mathrm{Cd}$} & Food - Control & 0,3 & 0,6 & 0,2 & 1,4 & 0,0 & 1,4 & 0,0 & 0,0 & 1,5 & 0,0 & 0,2 & 1,6 & 0,5 & 0,6 & 0,1 \\
\hline & Food - Soluble & 0,7 & 0,8 & 1,2 & 0,7 & 0,8 & 1,2 & 0,9 & 0,9 & 1,7 & 2,0 & 0,0 & 2,3 & 0,0 & 0,0 & 1,9 \\
\hline & Food - NP & 1,2 & 0,6 & 2,3 & 2,7 & 3,0 & 0,0 & 1,9 & 2,0 & 1,9 & 2,0 & 1,5 & 2,4 & 0,7 & 2,7 & 2,5 \\
\hline & Water - Control & 0,0 & 2,7 & 0,0 & 0,4 & 0,9 & 2,0 & 0,1 & 0,0 & 0,0 & 0,2 & 0,6 & 1,0 & 0,8 & 0,2 & 0,0 \\
\hline & Water-Soluble & 1,0 & 0,0 & 1,9 & 0,3 & 0,6 & 2,8 & 1,9 & 1,1 & 0,4 & 1,9 & 1,6 & 0,3 & 0,6 & 1,4 & 1,3 \\
\hline & Water - NP & 2,8 & 2,0 & 2,2 & 0,0 & 1,0 & 2,4 & 2,3 & 2,4 & 2,7 & 2,2 & 2,6 & 0,0 & 2,9 & 0,8 & 1,5 \\
\hline
\end{tabular}

Table II: S-value of each biomarker, within each experiment. Comparisons across different experiments are not allowed (they are nonsense). Highest values of biomarkers represent the highest induction/inhibition level obtained in an experiment. Grey cells correspond to biomarkers that were not measured in a particular experiment. 
Supplementary Material

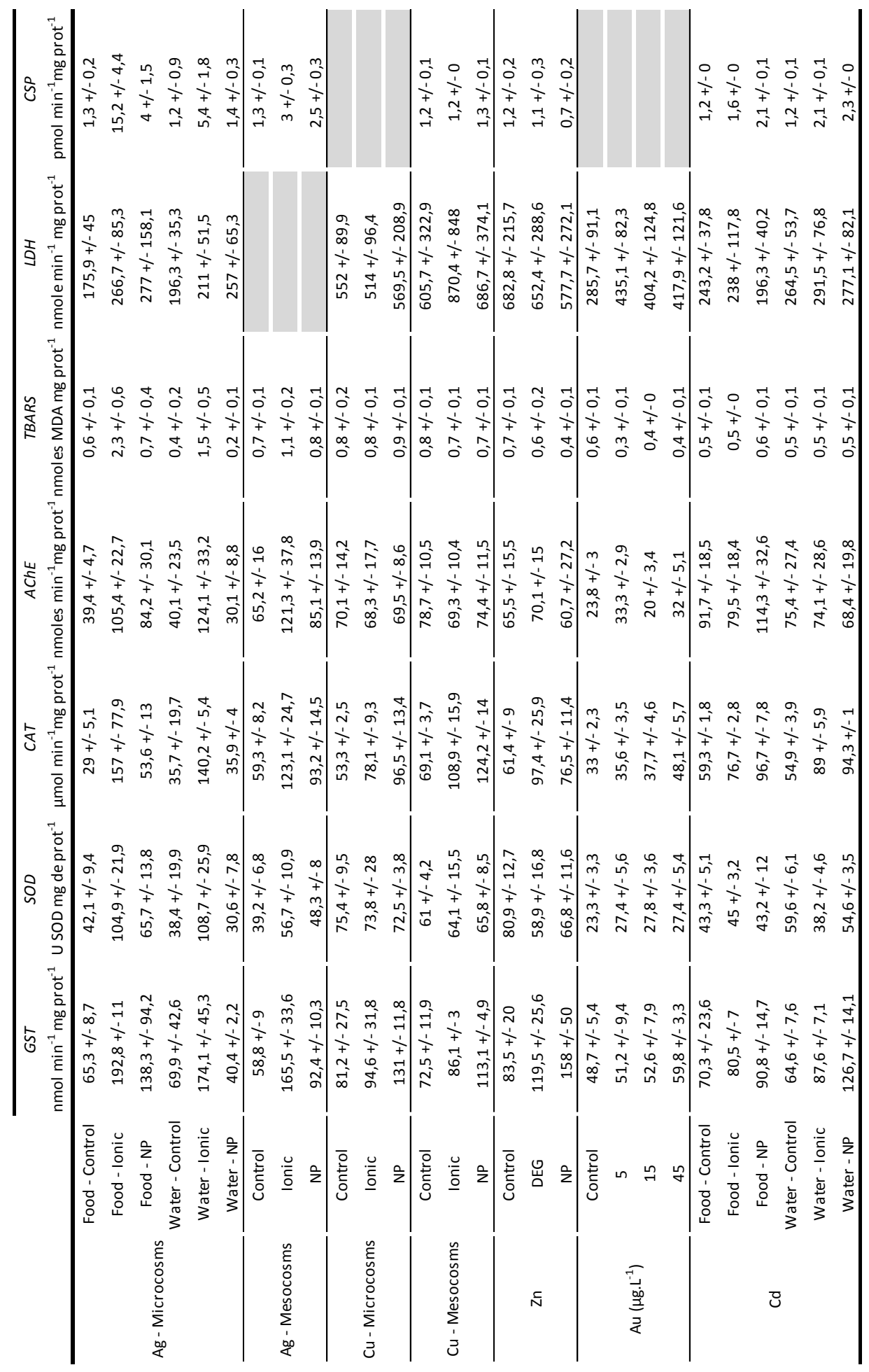

Table S1: Means (and SD between brackets) of biomarkers quantified in Hediste diversicolor for each experiment. GST: Glutathione-S-Transferase, SOD: superoxide dismutase, TBARS: thiobarbituric acid reactive substances, CSP: caspase, AChE: Acetylcholinesterase activity, LDH: Lactate dehydrogenase activity. 


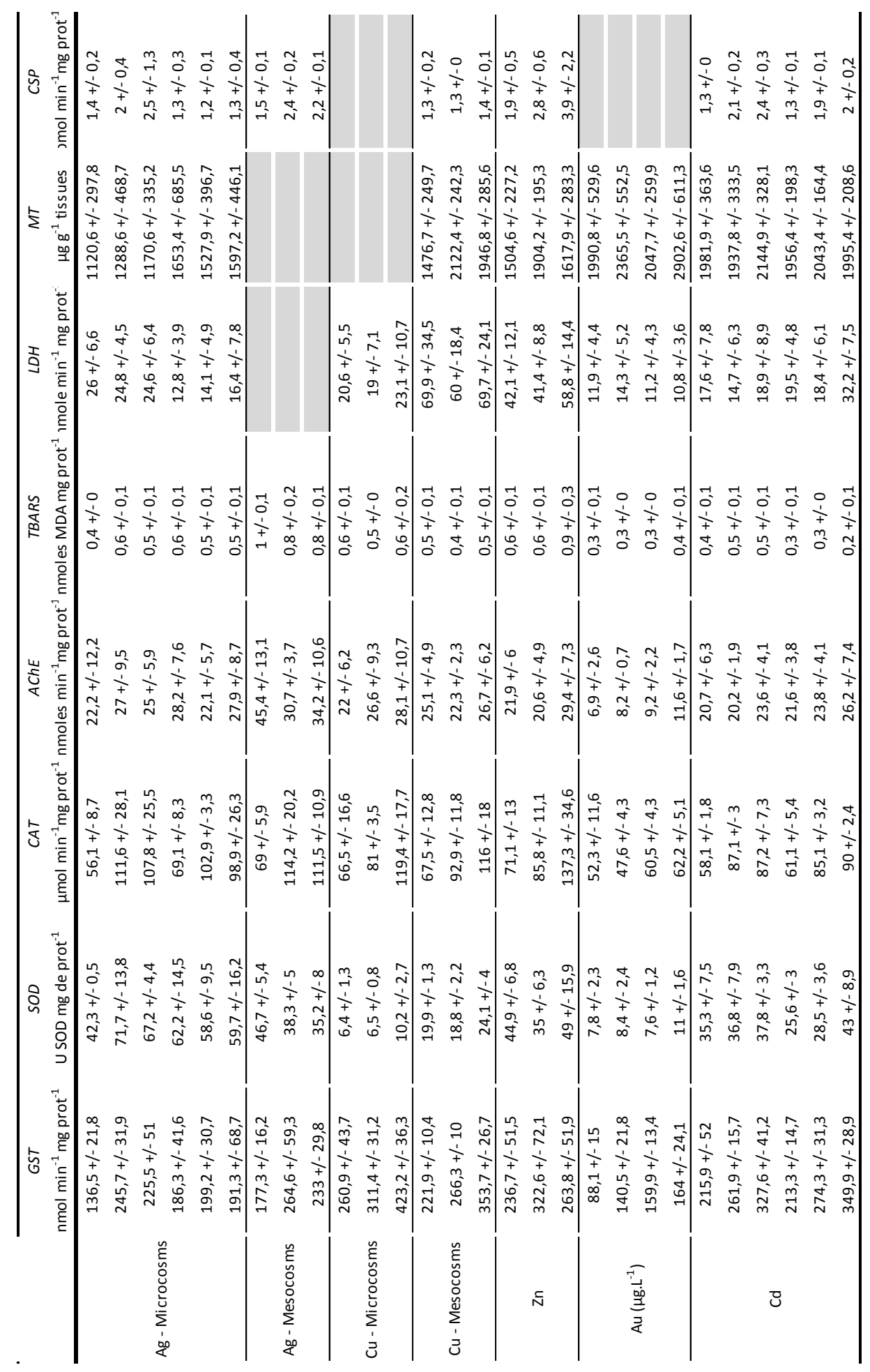

Table S2: Means (and SD between brackets) of biomarkers quantified in Scrobicularia plana for each experiment. GST: Glutathione-S-Transferase, SOD: superoxide dismutase, TBARS: thiobarbituric acid reactive substances, CSP: caspase, AChE: Acetylcholinesterase activity, LDH: Lactate dehydrogenase activity. 